tuổi càng cao thì nguy cơ, số lượng bênh nhân thiếu cơ càng tăng. Tuy nhiên, khi phân tích logistic đa biến thì tuổi không liên quan với thiếu cơ. Kết quả này khác với các nghiên cứu trước đó có thể do cõ̃ mẫu của chúng tôi chưa đủ lớn. Vân động là yếu tố có liên quan với thiếu cơ qua phép kiểm chi bình phương $(p<0,05)$, tương tự với kết quả nghiên cứu của tác giả Ken Sugimoto ${ }^{(5)}$. Mặt khác, trong nghiên cứu của tác giả Ken Sugimoto [5] khi phân tích về các thuốc điều trị ĐTĐ của nhóm dân số nghiên cứu, kết quả cho thấy dùng insulin là yếu tố có liên quan với thiếu cơ. Khi phân tích logistic đa biến, chúng tôi ghi nhận thời gian mắc bệnh ĐTÐ và thể trạng là hai yếu tố có liên quan với thiếu cơ. Kết quả này cũng tương tự với các nghiên cứu của các tác giả Ken Sugimoto, Foon Yin Fung đều kết luận thể trạng là yếu tố có liên quan với thiếu cơ $[5,7]$.

Hạn chế của nghiên cứu: đây là nghiên cứu quan sát, cỡ mẫu còn nhỏ và phần lớn bệnh nhân trong nghiên cứu là nam giới nên phần nào chưa phản ánh hết được tính đại diện cho dân số chung. Qua kết quả nghiên cứu này, có thể gợi ý cần các nghiên cứu toàn diện hơn trong tương lai.

\section{KẾT LUẬN}

Thiếu cơ chiếm tỷ lệ khoảng gần $1 / 4$ dân số người cao tuổi bị đái tháo đường típ 2. Thời gian bị đái tháo đường và thể trạng là hai yếu tố có liên quan đến thiếu cơ. Kết quả này gợi ý cần phải tầm soát thiếu cơ trên bệnh nhân cao tuổi bị đái tháo đường típ 2 để có hướng can thiệp phù hợp.

\section{TÀI LIỆU THAM KHẢO}

1. Cruz-Jentoft AJ, Baeyens JP, Bauer J M, et al (2010). Sarcopenia: European consensus on definition and diagnosis: Report of the European Working Group on Sarcopenia in Older People. Age Ageing, 39 (4): 412-23.

2. Wang $T$, Feng $X$, Zhou J, et al (2016). Type 2 diabetes mellitus is associated with increased risks of sarcopenia and pre-sarcopenia in Chinese elderly. Scientific reports, 6 .

3. Chen L. K, Liu I. K, Woo J, et al (2014). Sarcopenia in Asia: consensus report of the Asian Working Group for Sarcopenia. J Am Med Dir Assoc, 15 (2): 95-101.

4. Maria RR, Michelangela $B$, Ilaria $F$, at el (2016). Sarcopenia in Elderly Diabetic Patients: Role of Dipeptidyl Peptidase 4 Inhibitors. JAMDA 17: 896-901.

5. Ken S, Yasuharu T, Hiroshi $I$, at al (2019). Hyperglycemia in non-obese patients with type 2 diabetes is associated with low muscle mass: The Multicenter Study for Clarifying Evidence for Sarcopenia in Patients with Diabetes Mellitus. J Diabetes Investig, 10: 1471-1479.

6. Tanaka $S$, Kamiya $K$, Hamazaki $N$, et a (2017). Utility of SARC-F for Assessing Physical Function in Elderly Patients With Cardiovascular Disease. J Am Med Dir Assoc, 18 (2): 176-181.

7. Foon YF, Yi Ling EK, Rahul M (2019). Prevalence of and factors associated with sarcopenia among multi-ethnic ambulatory older Asians with type 2 diabetes mellitus in a primary care setting. BMC Geriatrics, 19: 122.

8. Lara Bianchi, Stefano Volpato (2016). Muscle dysfunction in type 2 diabetes: a major threat to patient's mobility and independence. Acta Diabetologic, 53: 879-889.

\title{
ĐÁNH GIÁ HIỆU QUẢ ĐIỀU TRI CỦA VIÊN NANG TAVINGA TRÊN BÊ̂NH NHÂN PHÌ ĐẠI LÀNH TÍNH TUYẾN TIỀN LIỆT
}

\begin{tabular}{|c|c|}
\hline \multicolumn{2}{|c|}{$\begin{array}{l}\text { Phạm Khắc Linh }{ }^{1}, \text { Đào Nguyên Mạnh }{ }^{1} \text {, Trần Thanh Tuấn }{ }^{1} \text {, } \\
\text { Quách Thị Quỳnh }{ }^{1} \text {, Nguyễn Việt } \text { Nam }^{2} \text {, Phạm Ngọc Quang1, Lê Văn Quang }\end{array}$} \\
\hline 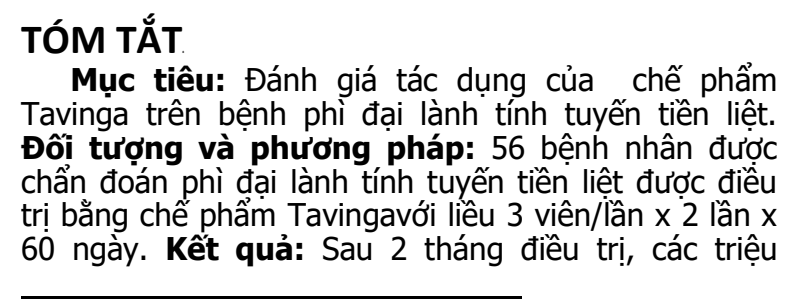 & 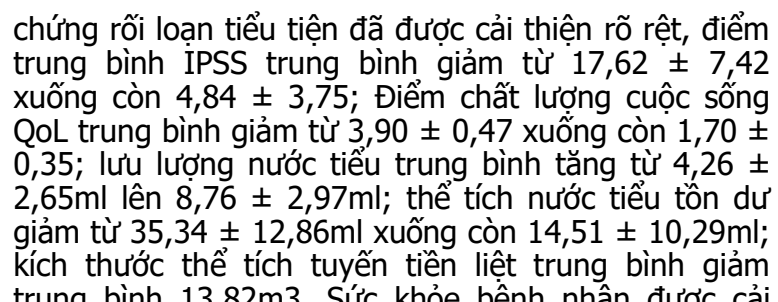 \\
\hline $\begin{array}{l}{ }^{1} \text { Trung } \\
{ }^{2} \text { Bệnh } \\
\text { Chịu tr } \\
\text { Email: }\end{array}$ & 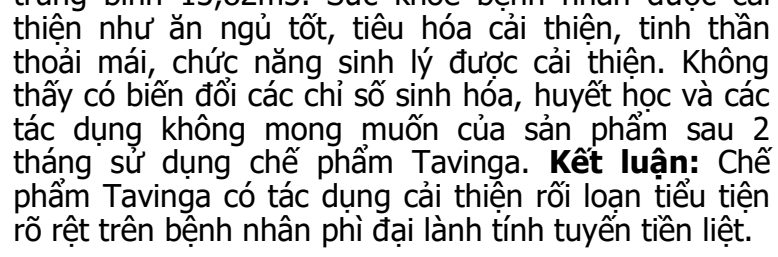 \\
\hline
\end{tabular}


Tư khóa: Chế phẩm Tavinga, phì đại lành tính tuyến tiền liệt, rối loạn tiểu tiện.

\section{SUMMARY \\ INVESTIGATION ON TREATMENT EFFECTS OF TAVINGA IN PATIENTS WITH BENIGN PROSTATIC HYPERTROPHY}

Objective: To investigate treatment effects of Tavinga in patients with benign prostatic hypertrophy $(\mathrm{BPH})$. Subjects and methods: 56 patients with $\mathrm{BPH}$ were treated by Tavinga at dose 3 tablets $\times 2$ times x 60 days. Results: At 2 months after treatments, urinary disfunctional symptoms of $\mathrm{BPH}$ ameliorated clearly: mean IPSS score decreased from $17,62 \pm 7,42$ to $4,84 \pm 3,75$; Mean QoL score decreased from $3,90 \pm 0,47$ to $1,70 \pm 0,35$; mean urine volume increased from $4,26 \pm 2,65 \mathrm{ml}$ to $8,76 \pm$ $2,97 \mathrm{ml}$, mean residual urine volume in the bladders decreased from $35,34 \pm 12,86 \mathrm{ml}$ to $14,51 \pm 10,29 \mathrm{ml}$; sizes of Prostate induced about $13 \mathrm{~cm}^{3}$. General health conditions of patients such as sleep, metal and other functions were better. There were no significant changes in biochemical and hematological indexes and no side effects. Conclusion: Treatment effects of Tavinga were clear in patients with $\mathrm{BPH}$.

Keywords: Tavinga, benign prostatic hypertrophy, urinary disfunctional symptoms.

\section{I. ĐẶT VẤN ĐỀ}

Phì đại lành tính tuyến tiền liệt (PĐLTTTL) là một bệnh phổ biến ở nam giới tuổi cao và các triệu chứng thường xuất hiện từ 50 tuổi trở lên. Tần suất mắc bệnh có xu thế ngày càng tăng cả trên thế giới cũng như ở Việt Nam. Giai đoạn đầu của bệnh chủ yếu gây rối loạn tiểu tiện, làm giảm chất lượng cuộc sống của người bệnh. Giai đoạn sau bệnh gây nhiều biến chứng nặng nề như suy thận và có thể gây tử vong [1].Việc điều trị PĐLTTL nhằm mang lại sự dể chịu, thoải máivà cải thiện chất lượng sống cho người bệnh. Điều trị nội khoa người ta thường dùng các thuốc ức chế alpha nhựa phazosin, xatran... Các phương pháp điều trị ngoại khoa như mổ mở bóc $u$, mổ nội soi cắt u, liệu pháp laser, sóng cao tần... Tuy nhiên việc sử dụng các thuốc tân dược và điều trị ngoại khoa cũng có nhiều biến chứng và tác dụng phụ không mong muốn [2]. Xu thế hiện nay, nhiêu nhà khoa học trong và ngoài nước tìm kiếm các chế phẩm có nguồn gốc từ động thực vật để điều trị PĐLTTTL. Samprost, Prostalamin, Verilut (LB Nga) có nguồn gốc từ tế bào tuyến tiền liệt của bê, bò. Permixon từ cây cọ lùn Nam Mỹ. Crila từ cây trinh nữ hoàng cung, Vương Bảo từ cây náng hoa trắng. Viện $Y$ sinh nhiệt đới/Trung tâm Nhiệt đới Việt - Nga đã nghiên cứu sản xuất thành công viên nang cứng "Tavinga" từ Bạch cương tàm có tác tăng cường sức khỏe, hỗ trợ điều tri. phì đại tuyến tiền liệt.
Bài báo trình bày kết quả nghiên cứuvề hiệu quả điều trị của chế phẩm Tavinga trên 56 bệnh nhân mắc bệnh phì đại lành tính tuyến tiền liệt năm 2020. Hy vọng kết quả nghiên cứu này góp phần làm phong phú thêm phương pháp điêu trị bệnh phì đại lành tính tuyến tiên liệt ở người cao tuổi.

\section{II. ĐỐI TƯƠ'NG VÀ PHƯƠNG PHÁP NGHIÊN CỨU}

2.1 Đối tượng nghiên cứu. Gồm 56 bệnh nhân nam >50 tuổi được chẩn đoán phì đại lành tính tuyến tiền liệt tại Trung tâm Nghiên cứu Điều trị Kỹ thuật cao, Viện Y sinh nhiệt đới từ tháng 7 đến tháng 11 năm 2020.

2.1.1. Tiêu chuẩn lựa chọn bệnh nhân. Thể tích tuyến tiền liệt $\geq 30 \mathrm{~cm}^{3}$, có rối loạn tiểu tiện được đánh giá theo thang điểm IPSS (International prostate symptom score) $\geq 7$; Điểm chất lượng cuộc sống QoL $\geq 3$; Lượng nước tiểu tồn dư < $100 \mathrm{ml}$; lưu lượng nước tiểu $<10 \mathrm{ml} /$ giây; Xét nghiệm PSA < $10 \mathrm{ng} / \mathrm{ml}$, ure, creatinin, ALT, AST máu bình thường.

2.1.2. Tiêu chuẩn loại trừ. Bệnh nhân nghi ngờ ung thư tuyến tiền liệt (PSA $\geq 10 \mathrm{ng} / \mathrm{ml}$ ); Bàng quang có sỏi, túi thừa, u; suy thận; bí đái hoàn toàn; thể tích nước tiểu dư $>100 \mathrm{ml}$; Bệnh nhân không tuân thủ theo quy trình điều trị.

2.2. Chất liệu nghiên cứu. Thành phần mỗi viên nang Tavinga có 450 mgbột Bạch Cương Tàm do Viện Y sinh nhiệt đới nghiên cứu sản xuất. Thành phần hóa học của chế phẩm gồm 17 acid amin, các nguyên tồ vi lượng như kẽm, selen, sắt, canxi, photpho... Sản phẩm Tavinga được đóng nang, đóng lọ 60 viên tại nhà xưởng đạt tiêu chuẩn GMP của công ty Công nghệ Dược phẩm Lotus. Kiểm nghiệm các chỉ tiêu vi sinh vật và kim loại nặng tại Viện Thực phẩm chức nằng đạt tiêu chuẩn cho phép theo quy định của Bộ Y tế [3].

\subsection{Phương pháp nghiên cứu}

2.3.1. Thiết kế nghiên cứu. Thử nghiêm lâm sàng, so sánh kết quả trước và sau điều trị

2.3.2. Phác đồ điêu trị. Các bệnh nhân được chẩn đoán PĐLTTTL đều được sử dụng viên nang Tavinga mỗi lần 3 viên sau bữa ăn, ngày 2 lân liên tục trong 60 ngày. Ngoài ra không uống bất cứ thuốc nào khác.

2.3.2. Phương pháp theo dõi và đánh giá hiệu quả điêuu trị. Đánh giá kết quả dựa vào 4 chỉ tiêu và chia làm 3 mức độ: tốt, khá và kém. Đánhgiá mức độ rối loạn tiểu tiện theo thang điểm IPSS và điểm chất lượng cuộc sống QoL; Lưu lượng nước tiểu; Thể tích nước tiểu tồn dư; Thể tích tuyến tiền liệt.

- Tốt: rối loạn tiểu tiện giảm (IPSS $\leq 7$ điểm; 
QoL $\leq$ 2điểm); Lưu lượng nước tiểu tăng > $2 \mathrm{ml} /$ giây; Thể tích nước tiểu tồn dư giảm $>50 \%$ và thể tích tuyến tiền liệt giảm> $15 \%$ hoặc trở về bình thường.

- Khá: rối loạn tiểu tiện giảm ít (IPSS giảm 1 mức độ; QoL IPSS giảm 1 mức độ); Lưu lượng nước tiểu tăng $=2 \mathrm{ml} /$ giây; Thể tích nước tiểu tồn dư giảm > 25- $50 \%$ và thể tích tuyến tiền liệt giảm từ 5 - 15\%.

- Kém: rối loạn tiểu tiện ít biến đổi; Lưu lương nước tiểu tằng $<2 \mathrm{ml} /$ giây; Thể tích nước tiểu tồn dư không thay đổi; thể tích tuyến tiền liệt giảm $<5 \%$.

2.4. Phân tích kết quả. Các chỉ số nghiên cứu được xử lý theo phương pháp thống kê y học bằng phần mềm IPSS 22.0. Sự khác biệt có ý nghĩa thống kê được xác định khi $p<0,05$.

\section{KẾT QUẢ NGHIÊN CỨU VÀ BÀN LUÂ̂N}

Bảng 1. Phân bố độ tuổi của các bệnh nhân tham gia nghiên cứu

\begin{tabular}{|c|c|c|}
\hline Độ tuồi & $\begin{array}{c}\text { Tuổi trung } \\
\text { bình }\end{array}$ & $\begin{array}{c}\text { Số lượng } \\
\text { (\%) }\end{array}$ \\
\hline$<60$ tuối & $56,50 \pm 3,53$ & $2(3,57 \%)$ \\
\hline $60-69$ tuối & $64,21 \pm 2,56$ & $29(51,79 \%)$ \\
\hline $70-79$ tuối & $73,72 \pm 2,54$ & $20(35,71 \%)$ \\
\hline$>80$ tuối & $83,60 \pm 3,18$ & $5(8,93 \%)$ \\
\hline Tống cộng & $69,08 \pm 7,27$ & $56(100 \%)$ \\
\hline
\end{tabular}

Nhận xét: Tuối trung bình của các bệnh nhân PĐLTTTL là: 69,08 \pm 7,27 (thấp nhất là 54 tuổi và cao nhất là 87 tuổi). Bệnh nhận PĐLTTTL gặp nhiều ở độ tuổi từ 60 đến 69 chiểm $51,79 \%$; tiếp đến là đổi tuổi từ $70-79(35,71 \%)$ và ít nhất là độ tuổi dưới 60 chiếm 3,57\%.

Bảng 2. Mức độ rối loạn tiểu tiện theo thang điểm IPSS trước và sau điều trị

\begin{tabular}{|c|c|c|c|c|}
\hline \multirow{2}{*}{$\begin{array}{c}\text { Mức độ rối loạn tiểu tieện theo } \\
\text { thang điểm IPSS }\end{array}$} & \multicolumn{2}{|c|}{ Trước điêu trị $(n=56)$} & \multicolumn{2}{|c|}{ Sau điều trị $(n=56)$} \\
\hline & Số lượng & Tỷ lệ (\%) & Số lượng & Tỷ lệ (\%) \\
\hline Nhẹ (0 - 7 điếm) & 5 & 8,93 & 39 & 69,64 \\
\hline Trung bình (8 - 19 điếm) & 29 & 51,78 & 17 & 30,36 \\
\hline Năng (20 - 35 điếm) & 22 & 39,29 & 0 & 0 \\
\hline Diếm IPSS trung bình $(X \pm S D)$ & \multicolumn{2}{|c|}{$17,62 \pm 7,42$} & \multicolumn{2}{|c|}{$4,84 \pm 3,75$} \\
\hline Thống kê & & & & \\
\hline
\end{tabular}

Nhận xét: Kết quả tại bảng 2 cho thấy sau đợt điều trị, tỉ lệ bệnh nhân có mức rối loạn thiếu tiện nặng giảm từ 39,29\% xuống $0 \%$, ngược lại tỉ lệ bệnh nhân có mức rối loạn thiểu tiện nhẹ tăng từ $8,93 \%$ lên $69,64 \%$. Điểm IPSS trung bình giảm từ 17,62 $\pm 7,42$ xuống còn 4,84 $\pm 3,75$. Sự khác biệt có ý nghĩa thống kê với $p<0,001$. Kết quả này giảm 12,78 điểm, tương đương so với kết quả nghiên cứu của Trần Lập Công ở bệnh nhân PĐLTTL sau 6 tuần điều trị bằng bài thuốc trà tan "Thủy long" giảm 13,11 điểm và kết quả nghiên cứu của Hoàng Văn Huấn và CS, sau 20 ngày uống các chế phẩm peptit điêu hòa sinh học (Veziliut $0,2 \mathrm{~g}$; Vezugen $0,2 \mathrm{~g}$; Kristagen $0,2 \mathrm{~g}$ và Ventfort $0,2 \mathrm{~g} / \mathrm{ngày}$ ) do LB Nga sản xuất giảm 12,48 điểm [4].

Bảng 3. Mức độ rối loạn tiểu tiện theo điểm chất lượng cuộc sống (QoL)

\begin{tabular}{|c|c|c|c|c|}
\hline \multirow{2}{*}{$\begin{array}{l}\text { Mức độ rối loạn } \\
\text { tiểu tiện theo QoL }\end{array}$} & \multicolumn{2}{|c|}{ Trước điêu trị $(n=56)$} & \multicolumn{2}{|c|}{ Sau điêu trị $(n=56)$} \\
\hline & Số lượng & Tỷ lệ (\%) & Số lượng & Tỷ lệ (\%) \\
\hline Nhẹ (0 - 2 điếm) & 0 & & 48 & 85,71 \\
\hline Trung bình ( $3-4$ điểm) & 45 & 80,36 & 8 & 14,29 \\
\hline Nặng (5 - 6 điểm) & 11 & 19,64 & 0 & 0 \\
\hline Điếm QoL trung bình $(X \pm S D)$ & \multicolumn{2}{|c|}{$3,9 \pm 0,47$} & \multicolumn{2}{|c|}{$1,7 \pm 0,35$} \\
\hline Thống kê & & & & \\
\hline
\end{tabular}

Nhận xét: Kết quả tại bảng 3 cho thấy sau đợt điểu trị, tỉ lệ bệnh nhân có mức rối loạn thiểu tiện nặng giảm từ 39,29\% xuống $0 \%$, ngược lại tỉ lệ bệnh nhân có mức rối loạn thiểu tiện nhe tăng từ $8,93 \%$ lên $69,64 \%$. Điểm QoL trung bình giảm từ $3,90 \pm 0,47$ xuống còn 1,70 $\pm 0,35$. Sự khác biệt có ý nghĩa thống kê với $p<$ 0,001 . Kết quả QoL trong nghiên cứu này giảm
2,2 điếm, cao hơn so với kết quả nghiên cứu của Hoàng Văn Huấn và $C S$, sau 20 ngày uống các chế phẩm peptit điều hòa sinh học (Veziliut $0,2 \mathrm{~g}$; Vezugen $0,2 \mathrm{~g}$; Kristagen $0,2 \mathrm{~g}$ và Ventfort $0,2 \mathrm{~g} / \mathrm{ngày}$ ) do LB Nga sản xuất giảm 1,57 điểm và kêt quả nghiên cứu của Trần Lập Công ở bệnh nhân PĐLTTTL sau 6 tuần điều trị bằng bài thuốc trà tan "Thủy long" giảm 1,9 điểm [4].

Bảng 4. Biến đổi lưu lượng nước tiểu trước và sau điều trị

\begin{tabular}{|c|c|c|c|c|}
\hline \multirow{2}{*}{$\begin{array}{c}\text { Lưu lượng nước tiểu } \\
\text { (ml/giây) }\end{array}$} & \multicolumn{2}{|c|}{ Trước điều trị $(\mathbf{n}=\mathbf{5 6})$} & \multicolumn{2}{c|}{ Sau điều trị $(\mathbf{n}=\mathbf{5 6})$} \\
\cline { 2 - 5 } & Số lượng & Tỹ lệ (\%) & Số lượng & Tỷ lệ (\%) \\
\hline$<2 \mathrm{ml} /$ giây & 9 & 16,07 & 0 & 0 \\
\hline
\end{tabular}




\begin{tabular}{|c|c|c|c|c|}
\hline $2-<5 \mathrm{ml} /$ giây & 22 & 39,29 & 15 & 26,78 \\
\hline $5-<10 \mathrm{ml} /$ giây & 20 & 35,71 & 29 & 51,79 \\
\hline$\geq 10 \mathrm{ml} /$ giây & 5 & 8,93 & 12 & 21,43 \\
\hline Lưu lượng nước tiểu trung bình $(X \pm S D)$ & \multicolumn{2}{|c|}{$4,26 \pm 2,65$} & \multicolumn{2}{|c|}{$8,76 \pm 2,97$} \\
\hline
\end{tabular}

Nhận xét. Kết quả tại bảng 4 cho thấy sau 2 tháng điều trị, tỉ lệ bệnh nhân có lưu lượng nước tiểu $<2 \mathrm{ml} /$ giây và từ $2-<5 \mathrm{ml} /$ giây giảm từ $16,07 \%$ và $39,29 \%$ xuống $0 \%$ và $26,78 \%$. Trong khi các bệnh nhân có lưu lượng nước tiểu từ 5 $<10 \mathrm{ml} /$ giây và $\geq 10 \mathrm{ml} /$ giây lại tăng từ $25,71 \%$ và $8,93 \%$ lên $51,79 \%$ và $21,43 \%$. Lưu lượng nước tiểu trung bình sau điều trị tăng từ 4,26 \pm 2,65 lên $8,76 \pm 2,97$. Sự khác biệt có ý nghĩa thống kê với $\mathrm{p}<0,001$. Lưu lượng nước tiểu trong nghiên cứu này tăng $4,5 \mathrm{ml}$ cao hơn so với kết quả nghiên cứu của Trần Lập Công ở bệnh nhân PĐLTTTL sau 6 tuần điều trị bằng bài thuốc trà tan "Thủy long" tăng 3,4 ml và tương đương với kết quả nghiên cứu của Hoàng Văn Huấn và CS, sau 20 ngày uống các chế phẩm peptit điều hòa sinh học (Veziliut $0,2 \mathrm{~g}$; Vezugen $0,2 \mathrm{~g}$; Kristagen $0,2 \mathrm{~g}$ và Ventfort $0,2 \mathrm{~g} / \mathrm{ngày}$ ) do LB Nga sản xuất tăng 4,2ml [4].

Bảng 5. Biến đổi nước tiểu tồn dư trước và sau điều trị

\begin{tabular}{|c|c|c|c|c|}
\hline \multirow{2}{*}{$\begin{array}{c}\text { Thể tích nước tiểu tồn dư } \\
(\mathrm{ml})\end{array}$} & \multicolumn{2}{|c|}{ Trước điều tri (n = 56) } & \multicolumn{2}{|c|}{ Sau điêu trị $(n=56)$} \\
\hline & Số lượng & Tỷ lệ (\%) & Số lượng & Tỷ lệ (\%) \\
\hline 0 & 0 & 0 & 8 & 14,29 \\
\hline$<10 \mathrm{ml}$ & 6 & 10,71 & 24 & 42,86 \\
\hline $10-<40 \mathrm{ml}$ & 19 & 42,86 & 20 & 35,71 \\
\hline$\geq 40 \mathrm{ml}$ & 31 & 46,43 & 4 & 7,14 \\
\hline Điểm trung bình thế tích tồn dư $(X \pm S D)$ & \multicolumn{2}{|c|}{$35,34 \pm 12,86$} & \multicolumn{2}{|c|}{$14,51 \pm 10,29$} \\
\hline Thống kê & \multicolumn{4}{|c|}{$p<0,001$} \\
\hline
\end{tabular}

Nhân xét: Sau 2 tháng điều tri, thế tích nước quả nghiên cứu của Trần Lâp Công ở bênh nhân tiểu tồn dư của các bệnh nhân giảm từ 35,34 \pm $12,86 \mathrm{ml}$ xuống còn $14,51 \pm 10,29 \mathrm{ml}$. Sự khác biệt có ý nghĩa thống kê với $p<0,001$. Tỉ lệ bệnh nhân cóthể tích nước tiểu tồn dư $\geq 40 \mathrm{ml}$, giảm từ 46,43\% xuống 7,14\%. Trong khi tỉ lệ bệnh nhân có thể tích nước tiểu tồn dư $<10 \mathrm{ml}$, tăng từ $10,71 \%$ lên $42,86 \%$, đăc biệt có $14,29 \%$ bênh nhân có thể tích nước tiểu dư bằng $0 \mathrm{ml}$. Sự khác biệt có ý nghĩa thống kê với $p<0,001$.

Kết quả nghiên cứu này tương đương với kết PĐLTTTL sau 6 tuần điều trị bằng bài thuốc trà tan "Thủy long" thể tích nước tiểu tồn dư của các bệnh nhân giảm từ 38,98 $\pm 11,93 \mathrm{ml}$ xuống còn $16,13 \pm 10,74 \mathrm{ml}$ và kết quả nghiên cứu của Hoàng Văn Huấn và CS, sau 20 ngày uống các chế phẩm peptit điều hòa sinh học (Veziliut $0,2 \mathrm{~g}$; Vezugen $0,2 \mathrm{~g}$; Kristagen $0,2 \mathrm{~g}$ và Ventfort $0,2 \mathrm{~g} /$ ngày) do LB Nga sản xuất, thể tích nước tiểu tồn dư của các bệnh nhân giảm từ 38,8 \pm $11,9 \mathrm{ml}$ xuống còn $16,3 \pm 9,4 \mathrm{ml}[4,5]$.

Bảng 6. Biến đổi thể tích tuyến tiền liệt trước và sau điều trị

\begin{tabular}{|c|c|c|c|c|}
\hline \multirow{2}{*}{$\begin{array}{l}\text { Thể tích tuyến tiền liệt } \\
\qquad(\mathrm{cm} 3)\end{array}$} & \multicolumn{2}{|c|}{ Trước điều trị $(\mathrm{n}=56)$} & \multicolumn{2}{|c|}{ Sau điều trị $(n=56)$} \\
\hline & Số lượng & Tỷ lệ (\%) & Số lượng & Tỷ lệ (\%) \\
\hline$<30 \mathrm{~cm}^{3}$ & 0 & 0 & 17 & 30,36 \\
\hline $30-<40 \mathrm{~cm}^{3}$ & 15 & 26,78 & 16 & 28,58 \\
\hline $40-<50 \mathrm{~cm}^{3}$ & 17 & 30,36 & 12 & 21,42 \\
\hline$\geq 50 \mathrm{~cm}^{3}$ & 24 & 42,86 & 11 & 19,64 \\
\hline Thể tích trung bình $T T L(X \pm S D)$ & \multicolumn{2}{|c|}{$50,82 \pm 17,36$} & \multicolumn{2}{|c|}{$37,00 \pm 14,84$} \\
\hline Thống kê & \multicolumn{4}{|c|}{$p<0,001$} \\
\hline
\end{tabular}

Nhận xét: Sau 2 tháng điều trị, thể tích tuyến tiền liệt của các bệnh nhân giảm từ 50,82 $\pm 17,36 \mathrm{~cm}^{3}$ xuống còn $37,00 \pm 14,84 \mathrm{~cm}^{3}$, giảm trung bình $13,82 \mathrm{~cm}^{3}$. Sự khác biệt có ý nghĩa thống kê với $\mathrm{p}<0,001$. Tỉ lệ bệnh nhân có thể tích tuyến tiền liệt $\geq 50 \mathrm{~cm}^{3}$ giảm từ $42,86 \%$ xuống 19,64\%. Sự khác biệt có ý nghĩa thống kê với $p<0,001$. Trong khi đó, thể tích tuyến tiền liệt $<30 \mathrm{~cm}^{3}$ tăng từ $0 \%$ lên 30,36\%. Sự khác biệt có ý nghĩa thống kê với $p<0,001$.

Kết quả thể tích tuyến tiền liệt của các bệnh nhân sau điều trị trong nghiên cứu này giảm tương đương với kết quả nghiên cứu của Trần Lập Công sau 6 tuần điều trị bằng bài thuốc trà tan "Thủy long", thể tích tuyến tiên liệt của các bệnh nhân giảm từ $40,54 \pm 7,01 \mathrm{~cm}^{3}$ xuống còn 
$28,02 \pm 6,44 \mathrm{~cm}^{3}$, giảm trung bình $12,52 \mathrm{~cm}^{3}$ và cao hơn kết quá nghiên cứu của Hoàng Văn Huấn và $\mathrm{CS}$, sau 20 ngày uống các chế phẩm peptit điều hòa sinh học (Veziliut $0,2 \mathrm{~g}$; Vezugen $0,2 \mathrm{~g}$; Kristagen $0,2 \mathrm{~g}$ và Ventfort $0,2 \mathrm{~g} / \mathrm{ngày}$ ) do LB Nga sản xuất,thể tích tuyến tiền liệt của các bệnh nhân giảm từ $43,57 \pm 12,72 \mathrm{~cm}^{3}$ xuống còn $37,91 \pm 9,79 \mathrm{~cm}^{3}$, giảm trung bình $5,66 \mathrm{~cm}^{3}[4,5]$.

Bảng 7. Đánh giá chung kêt quả sau điều trị

\begin{tabular}{|c|c|c|}
\hline Kết quả điều trị & Số bệnh nhân & Tỷ lệ (\%) \\
\hline Tốt & 46 & 82,14 \\
\hline Khá & 10 & 17,86 \\
\hline Kém & 0 & 0 \\
\hline
\end{tabular}

Sau điều trị có $100 \%$ số BN đạt kết quả tốt và khá, trong đó $82,14 \% \mathrm{BN}$ đạt kết quả tốt và 17,86\% BN đạt kết quả khá, không có trường hợp nào đạt kết quả kém. Kết quả này cao hơn kết quả nghiên cứu của Trân Lập Công sau 6 tuần điều trị bằng bài thuốc trà tan "Thủy long", kết quả tốt và khá đạt chỉ đạt $87,2 \%$, đáng lưu ý là có $12,8 \%$ đạt kết quả kém. Kết quả này cũng tương đương với kết quả nghiên cứu của Hoàng Văn Huấn và CS, sau 20 ngày uống các chế phẩm peptit điều hòa sinh học (Veziliut $0,2 \mathrm{~g}$; Vezugen $0,2 \mathrm{~g}$; Kristagen $0,2 \mathrm{~g}$ và Ventfort $0,2 \mathrm{~g} / \mathrm{ngày}$ ) do LB Nga sản xuất.

Bảng 8. Tác dụng của chế phẩm Tavinga lên sức khỏe toàn thân

\begin{tabular}{|c|c|c|c|c|}
\hline Các chỉ tiêu & $\begin{array}{c}\text { Sau tuấn } \\
\text { thứ 1 }\end{array}$ & $\begin{array}{c}\text { Sau tuân } \\
\text { thứ 2 }\end{array}$ & $\begin{array}{c}\text { Sau tuân } \\
\text { thứ 4 }\end{array}$ & $\begin{array}{c}\text { Sau tuấn } \\
\text { thứ 8 }\end{array}$ \\
\hline Cảm nhận sức khóe tốt lên & 15 & 48 & 56 & 56 \\
\hline Ngủ tốt hơn & 9 & 45 & 49 & 49 \\
\hline Án ngon miệng hơn & 10 & 42 & 53 & 53 \\
\hline Tiêu hóa cải thiện tốt hơn & 0 & 5 & 46 & 53 \\
\hline Cải thiện chức năng tình dục & 2 & 20 & 44 & 44 \\
\hline
\end{tabular}

Nhận xét: Kết quả cho thấy, theo thời gian, sức khỏe toàn thân của các BN được cải thiện tốt lên, $100 \%$ BN sau 4 tuần cảm nhận thây sức khỏe tốt lên, đa số các BN sau đợt điều trị cảm thấy ăn ngon miệng hơn, ngủ sâu hơn, tiêu hóa ổn định. Đăcc biệt, có 44 BN cải thiện chức năng tình duc như tăng ham muốn tình dục, cải thiện độ cương của dương vật. Theo chúng tôi, thành phần chể phẩm Tavinga với 17 axit amin và nhiêu nguyến tố vi lượng, trong đó lượng kẽm đạt $56.2 \mu \mathrm{g} / \mathrm{g}$ có tác dụng tăng cường sức khỏe, sinh lực cho các bệnh nhân. Đây là những dấu hiệu tốt, cần tiếp tục đánh giá trong môtt nghiên cứu khác.

Bảng 9. Sự biến đổi các chi số huyết học trước và sau điều trị

\begin{tabular}{|c|c|c|c|}
\hline Các chỉ số xét nghiệm & $\begin{array}{c}\text { Trước điêuu trị } \\
(\mathbf{n}=\mathbf{5 6})\end{array}$ & $\begin{array}{c}\text { Sau điêu trị } \\
(\mathbf{n}=\mathbf{5 6})\end{array}$ & $\mathbf{p}$ \\
\hline Số lượng hồng cầu (T/L) & $4,68 \pm 0,56$ & $4,75 \pm 0,57$ & $>0,05$ \\
\hline Lượng huyết sắc tố (g/dL) & $14,2 \pm 1,21$ & $14,00 \pm 1,18$ & $>0,05$ \\
\hline Số lượng bạch câu (G/L) & $6,07 \pm 1,39$ & $6,55 \pm 1,30$ & $>0,05$ \\
\hline Số lượng BC đoạn (G/L) & $4,05 \pm 1,19$ & $4,35 \pm 1,30$ & $>0,05$ \\
\hline Số lượng BC lympho (G/L) & $1,72 \pm 0,59$ & $1,87 \pm 0,68$ & $>0,05$ \\
\hline Số lượng BC mono (G/L) & $0,30 \pm 0,21$ & $0,33 \pm 0,21$ & $>0,05$ \\
\hline Số lượng TC (G/L) & $228,91 \pm 37,61$ & $241 \pm 42,48$ & $>0,05$ \\
\hline
\end{tabular}

Sau điều trị, các chỉ số huyết học thay đối không đáng kể so với trước điều trị (với $p>0,05)$ và vẫn nằm trong giới hạn bình thường.

Bảng 10. Sự biến đổi các chi số sinh hóa chức năng gan, thận

\begin{tabular}{|c|c|c|c|}
\hline Các chỉ số xét nghiệm & $\begin{array}{c}\text { Trước điều trị } \\
(\mathbf{n}=\mathbf{5 6})\end{array}$ & $\begin{array}{c}\text { Sau điêu trị } \\
(\mathbf{n}=\mathbf{5 6})\end{array}$ & $\mathbf{p}$ \\
\hline AST $(\mathrm{U} / \mathrm{L})$ & $25,20 \pm 6,60$ & $27,44 \pm 6,89$ & $>0,05$ \\
\hline ALT $(\mathrm{U} / \mathrm{L})$ & $25,82 \pm 12,31$ & $26,64 \pm 12,59$ & $>0,05$ \\
\hline GGT $(\mathrm{g} / \mathrm{L})$ & $34,49 \pm 12,37$ & $36,76 \pm 15,92$ & $>0,05$ \\
\hline Ure $(\mu \mathrm{mol} / \mathrm{L})$ & $6,24 \pm 1,60$ & $6,47 \pm 1,21$ & $>0,05$ \\
\hline Creatinin $(\mu \mathrm{mol} / \mathrm{L})$ & $91,27 \pm 15,06$ & $94,00 \pm 13,72$ & $>0,05$ \\
\hline
\end{tabular}

Sau điều tri, các chỉ số đánh giá chức năng gan thânn so với trước điều trị không có sự khác biệt có ý nghĩa thống kê với p>0,05.

* Các tác dụng không mong muốn của viên nang Tavinga. Theo dõi trong quá trình điều trị cho thấy, chế phẩm Tavinga không thấy có biểu hiện di ứng, chán ăn, buồn nôn, đầy bụng, khó tiêu, và rối loạn tiêu hóa; không có hiện tượng nhức đầu, chóng mặt, rối loạn giấc ngủ hoặc mất ngủ... 


\section{KẾT LUẦN}

- Sau 2 tháng điều tri bằng chễ phẩm Tavinga trên 56 bệnh nhân phì đại lành tính tuyến tiên liệt, các triệu chứng rối loạn tiểu tiện đã được cải thiện rõ rệt, điểm trung bình IPSS trung bình giảm từ $17,62 \pm 7,42$ xuống còn $4,84 \pm 3,75$; Điểm chất lượng cuộc sống QoL trung bình giảm từ $3,90 \pm 0,47$ xuống còn $1,70 \pm 0,35$; lưu lượng nước tiểu trung bình tăng từ 4,26 $\pm 2,65$ lên 8,76 $\pm 2,97$; thể tích nước tiểu tồn dư giảm từ 35,34 \pm $12,86 \mathrm{ml}$ xuống còn $14,51 \pm 10,29 \mathrm{ml}$; kích thước thể tích tuyến tiền liệt trung bình giảm giảm trung bình $13,82 \mathrm{~cm}^{3}$. Sức khỏe bênh nhân được cải thiện như ăn ngủ tốt, tiêu hóa cải thiện, tinh thần thoải mái, chức năng sinh lý được cải thiện.

- Tavinga không các biến đổi các chỉ số sinh hóa, huyết học và không thây các tác dụng không mong muốn của sản phẩm sau 2 tháng điều trị.
TÀI LIỆ THAM KHẢO

1. Nguyễn Bửu Triều, Lê Ngọc Từ (2003), U phì đại lành tính tuyến tiền liệt," Bệnh học tiết niệu, Nhà Xuất bản Y học, Hà Nội, tr.400-498.

2. Trân Đức, Trân Đức Hòe (2000), Sử dung IPSS QoL và đo lưu lượng nước tiểu trong đánh giá kết quả phẫu thuật u phì đại lành tính tuyến tiên liệt, Tạp chí Y học thực hành 7-2000, tr. 32-35.

3. Quyêt định số 46/2007/QĐ-BYT ngày 19/12/2007 của Bộ Y tế về chỉ tiêu kim loại nặng, vi sinh vật gây hại trong thực phẩm và dược phẩm.

4. Trân Lập Công (2011), Ṅghiên cứu hiệu quả điều trị phì đại lành tính tuyến tiền liệt của trà tan "Thủy long", Luận án tiến sĩ y học, Nà Nội, 2011.

5. Hoàng Văn Huấn, Phạm Khẳc Linh, Nguyễn Như Nghĩa, Nguyễn Quốc Ân, Phạm Xuân Ninh, Ngô Thanh Nam, Pham Ngọc Quang (2012), Kết quả ứng dụng chể phẩm peptit điều hòa sinh học hỗ trợ điều trị cho những người có tiên sử tiếp xúc với chất đốc da cam/dioxin bi phì đai lành tính tuyến tiên liệt, Tạp chí Khoa học và Cồng nghệ nhiệt đới, số 01, 12-2012, tr. 85-93ं.

\section{BƯớC ĐẦU ĐÁNH GIÁ TÌNH TRANG MẤT NGỦ KHÔNG THỰC TỔN VÀ MộT Số YẾU TỐ LIÊN QUAN}

\section{TÓM TẮT}

Mục tiêu: Đánh giá tình trạng mất ngủ không thực tổn thể Tâm tỳ hư và một số yếu tố liên quan. Đối tượng và phương pháp: 60 bệnh nhân tuổi trên 18, được chẩn đoán xác định mất ngủ không thực tổn theo tiêu chuẩn ICD - 10, phù hợp chứng Thất miên thể tâm tỳ hư theo $\mathrm{Y}$ học cổ truyền, điều trị tại Bệnh viện Châm Cứu Trung ương và Bệnh viện Tuệ Tĩnh từ tháng 5/2019 đến 10/2019, không phẩn biệt giới tính, nghề nghiệp, tình nguyện tham gia nghiên cứu. Đánh giá đặc điểm chung các đối tượng nghiên cứu, triệu chứng lâm sàng liên quan giấc ngủ. Kết quả: $90 \%$ bệnh nhânmất ngủ có độ tuổi trên 40 , tuổi mắc bệnh trung bình $57,60 \pm 15,58$ tuổi. Thời gian mắc bệnh từ 3 tới 6 tháng chiếm tỷ lệ cao $(63,3 \%)$. Thời lượng giấc ngủ trung bình trong đêm đạt 4,02 \pm 0,53 (giờ). Điểm đánh giá chất lượng giấc ngủ PSQI trung bình 14,09 $\pm 2,22$ (điểm). Áp lực công việc, mâu thuẫn gia đình, tổn thất kinh tế là những nguyên nhân gây sang chấn tâm lý thường gặp ở các bệnh nhân nghiên cứu. Kết luận: Mất ngủ không thực tổn gây ảnh hưởng nhiều tới chất lượng cuộc sống, lao

${ }^{1}$ Bệnh viện Châm cứu Trung ương,

2Viện Y học cổ truyền Quân đồi

Chịu trách nhiệm chính: Nguyễn Đức Minh

Email: drminhchamcuu@gmail.com

Ngày nhận bài: 10/12/ 2020

Ngày phản biện khoa học: 8/1/2021

Ngày duyệt bài: 29/1/2021

\section{Nguyễn Đức Minh ${ }^{1}$, Nguyễn Vinh Quốc ${ }^{2}$}

động và sinh hoạt của người bệnh. Bệnh có liên quan tới tuổi, nghề nghiệp, tình trạng hôn nhân và tiên sử sang chấn tâm lý.

Tư khóa: Mất ngủ không thực tổn, thất miên.

\section{SUMMARY}

ASSESSMENT OF PATIENTS WITH

NONORGANIC INSOMNIA AND SOME RELATED FACTORS

Objectives: To evaluate the nonorganic insomnia with xinpixuand some related factors. Subjects and method: 60 volunteered patients aging over 18 years old, which were diagnosed with nonorganic insomnia by ICD-10, consistent with shimian of xinpixu by traditional medicine, were getting treatment at Central Acupuncture Hospital and Tue Tinh Hospital from 2019 May to 2019 October; irrespective of occupation, gender. Generalizing the characterization of the patients, sleep-related clinical symptoms. Results: $90 \%$ of insomnia patients were over 40 years old, the age average is $57,60 \pm 15,58$ (years) with $63.3 \%$ patients had the duration of illness from 3 to 6 months. The average sleep duration during the night was $4.02 \pm 0.53$ (hour). The averaged PSQI score was $14.09 \pm 2.22$. Working pressure, family conflicts, and economic losses are common causes of trauma in the study patients. Conclusion: Nonorganic insomnia affect the quality of life, labor and living of the patient. The disease is related to age, occupation, marital status and history of trauma.

Keywords: Nonorganic insomnia, shimian 